merged into an abnormal redness and then into a severe infiltration which remained sharply defined from the pale right side at the median line and which involved the uvula, the right anterior and posterior pillars, the tonsil and the right side of the posterior pharyngeal wall. Upon the right anterior pillar there was an oblong shallow ulceration with very irregular outline about as large as a silver three cent piece. In the immediate neighborhood of this ulceration as well as in other parts of the field of infiltration, a number of yellowish white and grayish white specks were to be seen, in places distinctly isolated, in others merging into indistinct whitish patches. At the base of the tongue on the right side was a similar irregular ulceration somewhat larger than the first; upon the tonsil a number of smaller irregular patches, which in places were confluent; upon the posterior pharyngeal wall also several filmy irregular whitish patches. Laryngoscopic examination showed the mucous membrane somewhat anæmic, the larynx otherwise apparently normal. In making a physical examination, a shorter and duller percussion note was noticeable over the left apex than over the right and a somewhat roughened expiration, beyond this I could detect nothing abnormal. After a repeated careful inspection, concurring with the opinion of Dr. Ricketts, I made a diagnosis of tuberculosis based upon the condition of the pharynx, and further assumed the unpleasant duty of notifying the husband and brother that, notwithstanding the present inactivity of the disease in the lungs a fatal and rapid termination was almost certain. They were greatly shocked and evidently incredulous. They expressed themselves as loath to accept this hopeless prognosis without further consultation and suggested that Dr. William Carson, in whose judgment they justly placed the greatest confidence, be called in. On the following morning Dr. Carson made a physical examination, as the result of which he upheld the diagnosis of tuberculosis, though he found the disease in the lungs at the time in an inactive condition,

The patient remained under my treatment for a week. Curetting, owing to the extent of the lesion, was not to be considered and the treatment was mainly directed towards relieving the suffering and facilitating nutrition. The application of cocaine and a 10 per cent. solution of menthol brought very transient relief; the cocaine had to be used each time before taking food and the menthol, when first applied, proved very painful; on the third day I began the insufflation of iodoform powder containing $1-16 \mathrm{gr}$. of morphine and was agreeably surprised at the amount of relief it afforded the patient. The effect lasted the greater part of the day so that she could swallow without pain till towards evening, and within the next three or four days there was a perceptible improvement in the condition of the pharynx. September 23, she determined to return home where she would be more comfortable and she undertook to have the insufflations, upon which she became dependent, properly carried out.

On November 13, a letter from her husband informed us that the morphine and iodoform had proven most efficaceous. The family physician was using it and she had not only experienced very great relief but much of the sore place had healed and that she was in hopes of complete recovery.

A letter of a little later date brought news that the physician, then in charge of the case, ridiculed the idea of tuberculosis and had undertaken to treat her free of charge in order to demonstrate the error of the diagnosis arrived at in Cincinnati.

On January 8, less than two months later, word was received from the patient's husband that she had sunken into a condition of exhaustion and had succumbed to the disease, having given birth to her child some ten days before her death. Death occurred, therefore, within four months from the time the condition first made itself felt in the pharynx.

In the present state of our knowledge the question so frequently raised as to whether tubercular lesions in the pharynx and larynx are ever primary, can hardly lead to a satisfactory issue. While such lesions occur apparently independently, there will always be some ground for the sceptical to stand upon, as for example in the case of Schach who inclines to the view that when the affection is present in the pharynx, the disease always exists in the body in a dormant state, even though it be impossible to de- monstrate it. Of far more :practical importance is the question: "Can tuberculosis be recognized with certainty from the local lesion alone?" As a matter of fact we know that these lesions do present themselves at times when constitutional symptoms either do not suffice to establish the diagnosis, or can not be detected at all, and we must then depend upon the local symptoms alone, for our diagnosis. Now in scanning the literature of the few cases reported, we find the lesion produced by tuberculosis in the pharynx possessed often of such distinctive features as to greatly facilitate the diagnosis; in fact. in the majority of these cases tubercular nodules themselves were plainly visible in the neighborhood of the ulcerations and were verified post-mortem by the microscope in several instances, a condition which is almost never seen in the larynx. The entirely different character of the tubercular ulcer from the ulcer caused by syphilis has been nicely pointed out by Fraenkel, and both he and Tsembert have so carefully described the changes produced by the progress of the affection in this tissue, as to render its recognition far less difficult. In what proportion of cases the nature of the disease can be detected in its incipiency may not yet be established, but its exceptionally rapid course in this region, no doubt. accounts for its more characteristic appearance. In the case above reported, the minute yellowish or grayish white specks scattered irregularly over the infiltration, isolated in places, in others becoming. confluent and blurred; the shallow irregular ragged ulcer, the general pallor of the mucous membrane surrounding the infiltration, the excessive dysphagia, seemingly out of proportion to the severity of the lesion, presented an array of symptoms corresponding so strikingly to those described by the above mentioned observers that although I had seen a similar condition but once before, it appeared to me impossible to mistake it for any other affection.

\section{PAPILLOMA OF EPIGLOTTIS, ETC.}

Read in the Section of Laryngology and Otology at the Forty-third Annual Meeting of the American Medical Association, held at Detroit. Mich., June, 1892 .

BY A. B. THRASHER, M.D., OF CINCINNATI, OHIO.

Miss Pearl S., æt. 17, Springfield, Ohio, was referred to me by Dr. Langdon, March 3, 1892. The vault of the pharynx was covered with adenoid tissue, rough and lobular, which extended from the region of Luschka's tonsil back and down over the posterior pharyngeal wall to a point on a level with the upper surface of the epiglottis. This tissue was apparently about half an inch thick in the center above, and gradually grew thinner as it extended downward and toward either side.

On pressing down the tongue a reddish glandular tumor was disclosed, which, on further examination proved to be attached to the epiglottis. The tumor was about the size of a large English walnut, the surface being divided at irregular intervals by deep seams and covered by small granulations, giving it somewhat the appearance of a large lobular strawberry. It was attached to the free border of the epiglottis, rather more on the upper than the under surface. The balance of the epiglottis presented a normal appearance as to both size and color. The weight of the neoplasm was so great as to press the epiglottis downward and its size so large as to completely shut off the under parts of the larynx from the laryngeal mirror. The voice was quite husky and a nervous cough had been present for some time. There was increasing dyspncea for some three months, this being really the symptom which caused the patient to seek relief.

After the epiglottic neoplasm had been removed (which 
of the larynx was revealed. The movement of the left vocal cord was considerably impaired by some small sessile growths in the ventricle and over the left ventricular band, macroscopically quite like the tumor on the epiglottis.

After the lapse of two months there is as yet no tendency toward a recurrence of any of this tissue (that in the nasopharynx and larynx having been removed by curette and galvano-cautery). No microscopic examination of the tissue was made, but the clinical history points to papillomata of larynx, while the pharyngeal growth seemed to differ in no respect from that which $I$ have in other cases classed as adenoid tissue.

\section{Discussion.}

Dr. Casselberry, Chicago:-Concerning the diagnosis of laryngeal neoplasms Felix Semon has called attention to the fact that carcinoma, tubercle, etc., may have superficial papillomatous excrescences and that in order to get a correct result by microscopic examination, its entire growth must be examined. It is because this is rarely possible during life or before radical operation that the microscopic diagnosis of laryngeal growths is so unsatisfactory concerning the removal of laryngeal papillomata; I am glad to hear the galvano-cautery advocated. At the International Congress at Washington, in 1887, I had the pleasure of opening a discussion on this subject, and my paper consisted chiefly in advocating a specially constructed electrode for destruction of small sessile papillomata located on, above, or beneath the vocal cord. The idea was then criticised, among others, by Mr. Lennox Browne, who hesitated to use this instrument below the line of the epiglottis; under cocaine, however, failed to see sufficient reason for such restriction. The electrode then exhibited has the correct laryngeal angle and descending arm has an anterior curve, the convexity of which assists in drawing forward the epiglottis. It is armed at the end with a short platinum loop from 4 to 6 inches in length, which can be bent to either side and made to impinge beneath the vocal cord when necessary. It has no shield because such only increases its bulk and interferes with vision, and because it is unnecessary, for the careful operator having introduced the instrument cold, will press the platinum loop outward against the neoplasm and away from the opposite side before heating it.

In certain cases it is superior to forcep because it will penetrate under illumination to points, such as the anterior commissure or beneath the cords, to which forceps, by reason of their larger size cannot pass, at least without obstruction to light and interference with vision.

Large growths, when possible, would best be removed by forceps and the base subsequently cauterized. The isnare would require great caution to be exercised to avoid possible dropping of the neoplasm into the trachea. Concerning cocaine, care is necessary, strong solutions -20 per cent. on cotton application, and 10 per cent. in spray, are required to anxsthetize the larynx. These are capable in susceptible individuals of producing dangerous toxic symptoms. Before operating the susceptibility of the patient to cocaine hould be tested at previous sittings; and if at the same time we train the patient by passing probes, etc., as was formerly customary before the use of cocaine, success will be more readily attained and by the use of less cocaine.

Dr. Casselberry, Chicago:-I would call attention to $\mathrm{Dr}$. DuBlois' method of operating, per vias naturales by the finger nail. I believe it to be perfectly feasible, the larynx is high in children and can be reached and the soft papillomatous growths thoroughly scraped out of the laryn $x$ by a long finger-nail. If necessary an anæsthetic could be given and the procedure facilitated by pushing the larynx upward from without by the other hand.

I am disposed to deprecate thyrotomy as dangerous and often unsatisfactory. I recall a case in which a structure subsequently formed which together with recurrence of the growth finally caused death one night when the tracheotomy tube accidentally became dislodged.

Also another case in which recurrence necessitated the wearing of an intubation tube for years. I am disposed to avoid thyrotomy as much as possible, dealing tentatively with them by tracheotomy, intubation, and intralaryngeal manipulation until the child grows older.

Dr. Gibson:-The remarks of the several gentlemen who have spoken, are evidence that we have had much the same experiences under like circumstances.

The small size of the electrode or canula as compared with the forceps renders it possible to see exactly what we are doing.

To prevent the loss of the growth, by falling into the trachea, I instruct the patient to take a full inspiration just before I sever the growth. The patient had been repeatedly instructed to do so during the period of training, and did not have any idea as to my purpose at the time of removal. The object of this precaution is quite obvious.

To prevent toxic effects of cocaine, it has been my practice to instruct every patient in which cocaine is used in the upper air passages to refrain from swallowing, and have never experienced any constitutional effects of the drug when this instruction was followed.

The remarks on the occasional disappearance of papilloma after the use of stimulant and astringent, brings to mind what has frequently been debated in my mind, viz.: During the years that I was engaged in general practice it was my custom, when asked the best way to remove warts from the hands, to instruet them to apply castor oil thoroughly, and invariably the warts would vanish in a very short time.

Dr. Seiss has seen laryngeal papillomata absorbed under applications of iodine, etc. In structure these growth are the same as the ordinary dermal warts, which are well known to undergo absorption under mild applications of silver nitrat $\triangleq$,etc.

Dr. Price Brown, Toronto, referred to a case of papilloma of left vocal cord, in a gentleman age 55 , who was compelled to use his voice as his daily occupation. This was relieved and contraction of the papilloma secured by applications of thuja occidentalis, followed by treating with 10 per cent. of menthol in cellulose. Also to a case of double fibroma of larynx in a gentleman aged 37, suffering at same time from aneurism of aorta, the one arising between right arytenoid and right ventricular band, and projecting inwards over the glottis, impeding respiration; the other springing from right side of larynx immediately beneath the vocal cord. Under cocaine these were removed at a number of different sittings by galvano-cautery points, with result of relieving the dyspnœa. Some time afterwards the patient died of aneurism of aorta. The larynx which I obtained at the postmortem exhibits the cicatrix of lower growth but not of the upper.

Dr. Lowman,Cleveland,0.:-A case of papilloma that passed under my observation proves that papillomata sometimes tend spontaneously to recovery. The patient was a child who had been hoarse for some months, and had rapidly grown dyspncic in the last few weeks immediately preceding his application for relief. When first seen the breathing was so difficult that the face was cyanotic.

Laryngoscopic examination revealed a growth almost filling the chink of the glottis. Prompt interference was necessary and was obtained by a tracheotomy. Pneumonia and a prolonged illness followed the operation. After the recovery of the patient from the acute disease, the growth was inspected and found to have diminished in size. Repeated examinations at intervals of a few weeks showed that the growth was gradually becoming smaller. In less than a year all evidence of its appearance had disappeared. There had been no treatment whatever, unless the rest the tumor gained by reason of the tracheotomy can be considered treatment. The air passes through the larynx rapidly, and especially when the glottis is partially filled, and the opening into the trachea very much contracted. For this reason it may be that the papillomata grow more rapidly or swell more rapidly as the breathing grows more difficult and the friction greater.

The case shows that a papilloma may disappear, providing the larynx has rest from the air currents.

It is likely that the papilloma that disappears under treatment with astringents would subside under volitional or partial rest of the larynx.

Dr. Wadler, Indianapolis, called attention to the need of preparatory treatment, and said it was his custom to use stypics and astringents at the time, and frequently has witnessed their disappearance under such treatment. He also wished to emphasize the suggestion of Dr. Casselberry, of great caution in the use of cocaine, as he had witnessed.dangerous symptoms in his early experience prior to his learning to exercise this great care.

Dr. Boylan said:- T have been interested in this case, in that I have one at present under treatment of a similar nature, excepting that the tumefaction is considerably larger: it being attached at and just below the anterior commissure and extending back so as to leave a comparatively small space for respiration posteriorly. The case was treated for asthma for some time till the tumefaction was finally discovered and came finally under my treatment. I hesitated for some time whether to perform tracheotomy at once or to attempt the removal through the pharynx. I finally decided 
to prepare for rapid tracheotomy and to then adopt the latter course. I succeeded in removing over one-half of the growth with the forceps, and thus averting the immediate danger of asphyxiation. Now while I appreciate all the advantages mentioned by the previous speakers in favor of the galvanocautery, I doubt if I shall be successful in reaching the remainder of the growth with the cautery, owing both to the age of the patient, who is a boy six years of age, and to the location of its attachment, and I am inclined to believe that I will stand better chances of reaching it with Schrotter's forceps.

\section{ORBITAL AND OCULAR GROWTHS.}

REPORT OF FOUR CASES WITH TWENTY-TWO PHOTOMICROGRAPHIC ILLUSTRATIONS.

Read in the Section of Ophthalmology at the Forty-third Annual Meet ing of the American MedicaI Association, held at Detroit, Mich., June, 1892.

\section{BY JOSEPH A. WHITE, A.M. M.D.,}

SENIOR SURGEON TO TIE RICHMOND, VA., EYE, EAR, THROAT AND NOSF IN FIRMARY.

AND WM. M. GR IY, M.D.

PATHOLOGIST OF TIIE ARMY MEDICAL MUSEUM, WASHINGTON, D. C.

I present these cases of tumors of the eye and orbit from my clinic at the Richmond,Va., Eye, Ear \& Throat Infirmary operated on during this year, 1892 , because I thought they were of sufficient interest for consideration. One is a case of melanotic sarcoma of the choroid that has as yet had no recurrence, but as this character of tumor is metastatic, there may be some manifestations of the same kind of growth elsewhere. The second is a sarcoma of the orbit which recurred twice after the original growth and eye were removed. The other two were growths of the orbit intimately connected with the perioste um; one in a woman 58 years of age, the other in a girl 16; one from the inner side of the orbit, extending from the orbital edge back and behind the eye to the sphenoidal fissure, the other from the external side following the same direction, and producing an apparently similar pathological condition of the eye and its annexes. Cases one and three were operated on by myself; cases two and four by Dr. John Dunn, Chief of Clinic at the Infirmary.

Case 1. Melanotic Sarcoma of the Choroid-Geo. W. Wingfield, aged 54 years consulted me first, May 30,1890. The left eye was blind, slightly exophthalmic, tension increased, the cornea clouded, the anterior chamber abolished, and the whole upper and outer part of the sclerotic of a dense black color. I diagnosed melanotic growth of the eye, and advised enucleation. This he declined to have done, and went home. I heard nothing from him until February 6, 1892 , when he presented himself at my office with the eye so enormously enlarged that the lids could not be closed over it, the whole of the sclerotic perfectly black; patient suffering constant and excruciating pain. I gave him the same advice as before, and he consented to the removal of the eye. As cocaine had very little effect in anæsthetizing the eye, I gave chloroform, althogh I rarely have recourse to anything but cocaine in enucleation, and removed the globe. It was so distended, I was obliged to split the outer canthus to get it out of the orbit. Fearing the growth extended backward along the optic nerve sheath I grasped the nerve with a stout pair of fixation forceps before I cut the eye loose, so as to draw it out, and remove as much of it as possible. This I did after enucleating the eye, drawing the nerve out with the forceps already in position as far as possible, then putting another pair behind them and pulling again hand over hand as it were, and in this way I cut off about three-quarters of an inch of the nerve.

The eye was placed in Muller's fluid and sent to Dr. Wm. M. Gray, pathologist of the Army Medical Museum in Washington, and I append his report of the condition of the eye. I saw this patient on May 30 when the socket was clean and no signs of recurrence. I inserted an artificial eye and he returned home.
Dr. Gray sent me the following report of his examination of the eye; with the accompanying photographic plates and microscopic slides, both prepared by him in his laboratory.

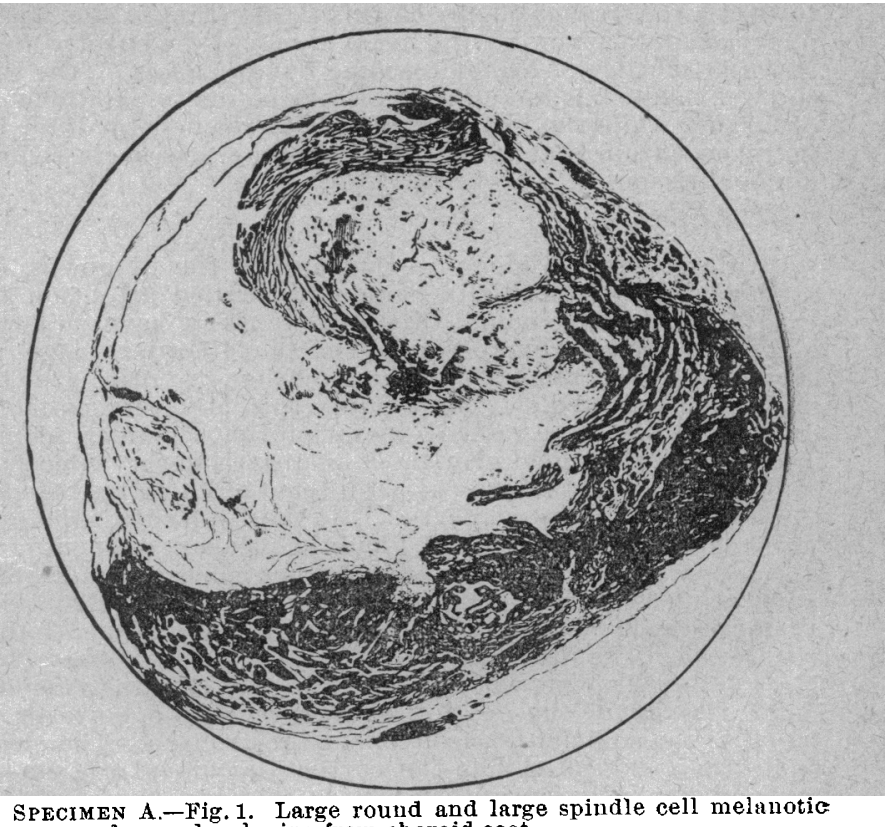

SPECIMEN A.-Fig. 1. Large round and large
sarcoma of eye; developing from choroid coat.

Fig. 1. Shows a longitudinal antero-posterior section through the entire eyeball, and its contained tumor.

The tumor is composed of two seemingly distinct masses; one an intensely pigmented growth forming the peripheral portion, and a central mass, which is very slightly pigmented. The outer pigmented portion is made up of large round, spindle and stellate pigment cells, with a few small

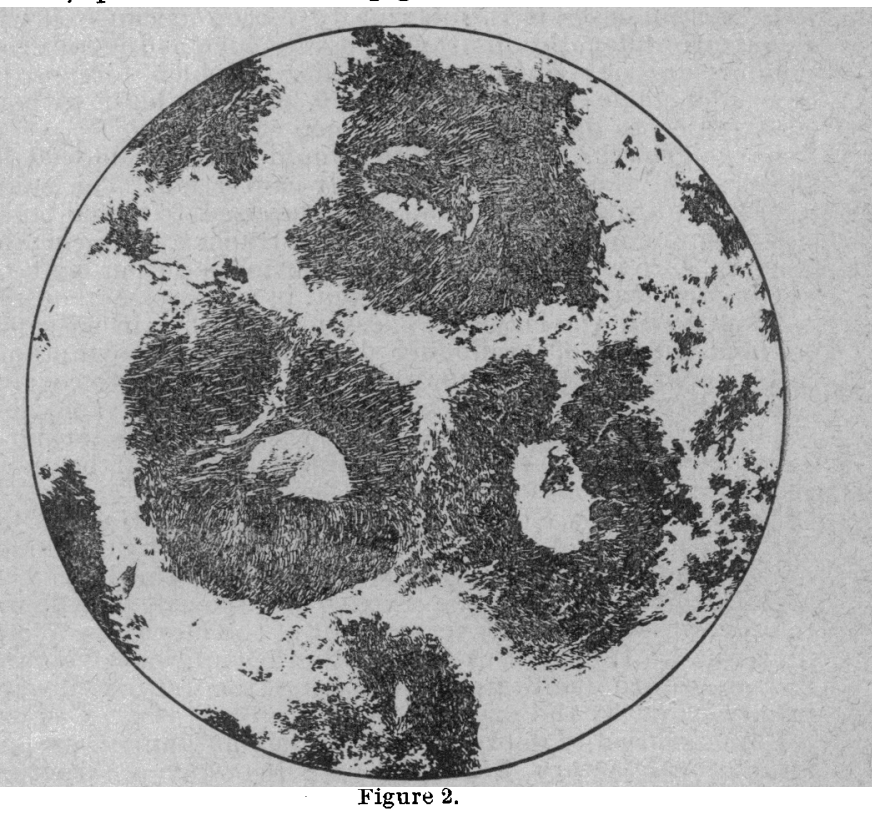

round unpigmented cells. The slightly pigmented central portion of the growth is composed of large round cells, somewhat epitheloid in appearance, and large spindle cells arranged in circular masses around small blood vessels; the walls of these blood-vessels are quite thick, and are composed of dense fibrous connective tissue. Fig's 2 and 3 show the circular cell masses in the slightly pigmented portion.

Fig. 4. one of the circular cell masses on the border of the dense pigment portion. Fig. 5 shows the large round cells composing the greater portion of the entire growth; it is taken on the border of the densely pigmented portion, and contains a number of large round pigment cells. Fig. 6 from the same locality shows the same cells with an irregu- 